\title{
AVALIE: MODELO DE AVALIAÇÃO DE SATISFAÇÃO DOS SOLICITANTES DE ATENDIMENTO AO CORPO DE BOMBEIROS MILITAR DO ESTADO DO RIO DE JANEIRO
}

\author{
Flávio Luiz de Castro Jesus ${ }^{1}$ \\ Verônica Santos Albuquerque ${ }^{2}$ \\ Larissa Veronesi Rainier Tiecher ${ }^{3}$ \\ Larissa Scabello Araújo Guimarães ${ }^{4}$ \\ Andréa Mamede Ximenes ${ }^{5}$ \\ Andréa Barros Leite ${ }^{6}$ \\ Cynthia Maria Fumo Mariano da Silva ${ }^{7}$ \\ Henry Sznejder ${ }^{8}$ \\ PaulusJosephus de Almeida Barbosa e Daco ${ }^{9}$ \\ Bianca de Souza Machado Mátos ${ }^{10}$
}

\section{RESUMO}

O presente artigo trata da elaboração e aplicação de um modelo de avaliação da satisfação dos solicitantes de socorro ao Corpo de Bombeiros Militar do Estado do Rio de Janeiro (CBMERJ), denominado Projeto AVALIE, desenvolvido durante o ano de 2017, cujos resultados passaram a servir de base para o planejamento de metas institucionais.Seu objetivo foi apresentar os resultados obtidos, por meio dos índices de satisfação dos usuários atendidos pelo CBMERJ, no que se refere ao acesso e à qualidade do atendimento telefônico no momento da solicitação do socorro, à percepção acerca do tempo-resposta, à cordialidade e à qualidade do atendimento prestado pelas guarnições. Além desses aspectos, também foram descritos resultados advindos da aplicação do Net Promoter Score(NPS), como método incorporado à metodologia do Projeto para mensurar a satisfação e a lealdade dos usuários dos serviços do CBMERJ.Diante da predominância absoluta de médias superiores a 9 nos aspectos avaliados e do reconhecimento do CBMERJ como um serviço público respeitável e eficiente, ficam evidentes a qualidade técnica e o comprometimento da tropa. Por meio do Projeto Avalie, é possível afirmar, com base numa análise sistematizada e atual, que o Corpo de Bombeiros Militar do Estado do Rio de Janeiro tem excelente aprovação dentre os usuários de seus serviços.realizadas.

Palavras-chave: Avaliação de Serviços; Qualidade; Satisfação do Consumidor

\footnotetext{
${ }^{1}$ Coronel do Corpo de Bombeiros Militar do Estado do Rio de Janeiro. Subcomandante Geral e Chefe do Estado-Maior Geral. E-mail: flcj1970@gmail.com

${ }^{2}$ Major do Corpo de Bombeiros Militar do Estado do Rio de Janeiro. Doutora em Ciências - ENSP/FIOCRUZ. E-mail: veronicatere@gmail.com

${ }^{3}$ Tenente do Corpo de Bombeiros Militar do Estado do Rio de Janeiro. E-mail: larissaveronesi@yahoo.com.br

${ }^{4}$ Major do Corpo de Bombeiros Militar do Estado do Rio de Janeiro. E-mail: larissasg@globo.com

${ }^{5}$ Capitão do Corpo de Bombeiros Militar do Estado do Rio de Janeiro. E-mail: ximenescbmerj@gmail.com

${ }^{6}$ Capitão do Corpo de Bombeiros Militar do Estado do Rio de Janeiro. E-mail: ableite6@gmail.com

${ }^{7}$ Capitão do Corpo de Bombeiros Militar do Estado do Rio de Janeiro. E-mail: cymariaf@gmail.com

${ }^{8}$ Tenente do Corpo de Bombeiros Militar do Estado do Rio de Janeiro. Mestre em Saúde Coletiva - UFRJ E-mail: doc.henrysz@gmail.com

${ }^{9}$ Tenente-Coronel do Corpo de Bombeiros Militar do Estado do Rio de Janeiro. E-mail: paulusdaco@gmail.com

${ }^{10} 3^{\circ}$ Sargento do Corpo de Bombeiros Militar do Estado do Rio de Janeiro. E-mail: biabombeirarj.bm@gmail.com
} 


\title{
AVALIE PROJECT: EVALUATION MODEL OF SATISFACTION AMONG THE RESCUE REQUESTERS TO CORPO DE BOMBEIROS MILITAR DO ESTADO DO RIO DE JANEIRO
}

\begin{abstract}
This article is about the elaboration and application of a model of satisfaction assessment among the rescue requesters to Corpo de BombeirosMilitar do Estado do Rio de Janeiro (CBMERJ), called "AVALIE Project", which was developed during 2017 and about how its results helped institutional goals planning. The aim of the article was to present the obtained results that included satisfaction indexes scored bythe requesters. These indexes presented the satisfaction with access and quality of the telephone service in the moment of the rescue request, the satisfaction with the response time, the cordiality and the quality of provided service by rescue team. In addition to these aspects, the article describes the results obtained by application of the Net Promoter Score (NPS), as a method to measure the satisfaction and reliability of requesters. The results reveled absolute predominance of averages above 9 in the evaluated aspects and the recognition of CBMERJ as a respectable and efficient public service. The technical quality and the commitment of the military firefighterswere evident. Through the Evaluate Project, it is possible to state, based on a systematized and current analysis, that CBMERJ has excellent approval among its services requesters.
\end{abstract}

Key words: Services Evaluation; Quality; Consumer Satisfaction

Artigo Recebido em 30/11/2017 e Aceito em 18/02/2018 


\section{INTRODUÇÃO}

O presente artigo trata da elaboração e aplicação de um modelo de avaliação da satisfação dos solicitantes de socorro ao Corpo de Bombeiros Militar do Estado do Rio de Janeiro (CBMERJ), denominado Projeto AVALIE, desenvolvido durante o ano de 2017, cujos resultados passaram a servir de base para o planejamento de metas institucionais.

A motivação para o desenvolvimento do Projeto AVALIE nasceu da ausência de referencial quantitativo que comprovasse a assertiva empírica de que o CBMERJ conta com forte aprovação da população para a qual presta serviços. A publicação mais próxima que se encontrava nesse aspecto era o Índice de Confiança Social (ICS), calculado e divulgado pelo Instituto Brasileiro de Opinião Pública e Estatística (IBOPE), cujo objetivo é medir a credibilidade de instituições brasileiras e grupos sociais, e que, desde 2009, apresenta o Corpo de Bombeiros ocupando o primeiro lugar como a instituição mais confiável do país.

Embora a liderança por sete anos consecutivos do Corpo de Bombeiros no ICS/IBOPE corrobore com a percepção tácita de satisfação da população com a corporação, a pesquisa que gera o referido índice é realizada em todo o Brasil com a população em geral, não sendo necessariamente entrevistadas pessoas que foram solicitantes/usuárias dos serviços prestados pelos Bombeiros.Permanecia, então, a inquietação de conhecer a real avaliação de quem necessitou do atendimento do CBMERJ nas suas diversas dimensões.

É fácil entrar em contato com o CBMERJ? Suas guarnições são eficientes aos olhos de quem solicitou atendimento? $\mathrm{O}$ tempo de chegada até $\mathrm{O}$ local do evento está dentro do esperado por aqueles que aguardam em situações de urgência? A percepção de qualidade do serviço prestado é semelhante ou varia de acordo com os diferentes tipos de eventos aos quais 0 CBMERJ responde? Quais os fatores que geram satisfação e/ou insatisfação entre os solicitantes de socorro? Esses questionamentos foram os motores do 
Revista Científica do Corpo de Bombeiros Militar de Pernambuco

Seção 1 - Artigos Técnico Científicos

Artigo publicado no Vol.04 №09 - Edição de JAN a JUN 2018 - ISSN 2359-4837(online)

Versão on-line disponível em: http://www.revistaflammae.com.

Projeto AVALIE, coordenado pelo Estado-Maior Geral do CBMERJ, que ouviu 3.883 pessoas que solicitaram socorro à corporação em 2016.

A construção da metodologia do referido projeto teve como premissa o emprego da satisfação como um componente importante da avaliação da qualidade e se baseou em dois enfoques teóricos apresentados por Esperidião e Trad (2006): a percepção de desempenho do serviço e a confirmação da expectativa por parte do usuário. Nesse contexto, o projeto AVALIE considerou a qualidade percebida e as expectativas dos solicitantes, que foram definidas por Borges Júnior e Fonseca (2002), respectivamente, como a avaliação da performance da instituição e o conhecimento acumulado dos indivíduos sobre a qualidade da oferta de serviços avaliados. Para os autores, os resultados de satisfação - ou insatisfação - surgem quando se comparam as percepções de performance de um produto/serviço com as expectativas/desejos dos indivíduos (consumidores ou usuários).

O objetivo do presente artigo é apresentar os resultados obtidos com o Projeto AVALIE por meio dos índices de satisfação dos usuários atendidos pelo CBMERJ no que se refere ao acesso e à qualidade do atendimento telefônico no momento da solicitação do socorro, à percepção acerca do tempo-resposta, à cordialidade e à qualidade do atendimento prestado pelas guarnições. Além desses aspectos, também serão descritos resultados advindos da aplicação do Net Promoter Score(NPS), como método incorporado à metodologia do Projeto para mensurar a satisfação e a lealdade dos usuários dos serviços do CBMERJ.

\section{METODOLOGIA}

Trata-se de pesquisa quantitativa, descritiva, cuja coleta de dados ocorreu por meio de entrevista estruturada através de contato telefônico com solicitantes de socorro no ano de 2016.

Para fins de cálculo amostral, tomou-se como universo todos os atendimentos registrados pelo Centro de Operações do Corpo de Bombeiros 
Revista Científica do Corpo de Bombeiros Militar de Pernambuco Seção 1 - Artigos Técnico Científicos

Artigo publicado no Vol.04 №09 - Edição de JAN a JUN 2018 - ISSN 2359-4837(online)

Versão on-line disponível em: http://www.revistaflammae.com.

(COCB) e pelo Centro de Operações GSE/SAMU (COGS) em 2016, cujos campos "telefone" e "identificação do quartel" estivessem preenchidos. Com base nesses critérios, chegou-se a uma amostra composta por um total de 12.611 solicitantes, dos quais 3.883 participaram da pesquisa, perfazendo uma conversão de $30,8 \%$. Foram contactados os solicitantes em função dos quartéis para os quais o Centro de Operações destinou as viaturas. Os desfechos dos telefonemas realizados estão apresentados natabela 01 :

Tabela 01: Desfecho das ligações realizadas pelo Projeto AVALIE de março a junho de 2017

\section{DESFECHO DAS LIGAÇÕES}

\begin{tabular}{lcc} 
Participante & 3.883 & $30,8 \%$ \\
Não atende & 4.956 & $39,3 \%$ \\
\hline Número inválido & 2.020 & $16,0 \%$ \\
\hline Número errado & 812 & $6,4 \%$ \\
\hline Solicitante não encontrado & 639 & $5,1 \%$ \\
Solicitante não quis avaliar & 152 & $1,2 \%$ \\
Solicitante não soube avaliar & 149 & $\mathbf{1 , 2} \%$ \\
TOTAL & $\mathbf{1 2 . 6 1 1}$ & $\mathbf{1 0 0 , 0} \%$
\end{tabular}

Os contatos telefônicos foram realizados de março a junho de 2017 por uma equipe de sete militares do Estado-Maior Geral a partir de roteiro de entrevista previamente padronizado, composto por quatro blocos de perguntas, conforme ilustrado na figura 01. 
Revista Científica do Corpo de Bombeiros Militar de Pernambuco Seção 1 - Artigos Técnico Científicos

Artigo publicado no Vol.04 No09 - Edição de JAN a JUN 2018 - ISSN 2359-4837(online)

Versão on-line disponível em: http://www.revistaflammae.com.

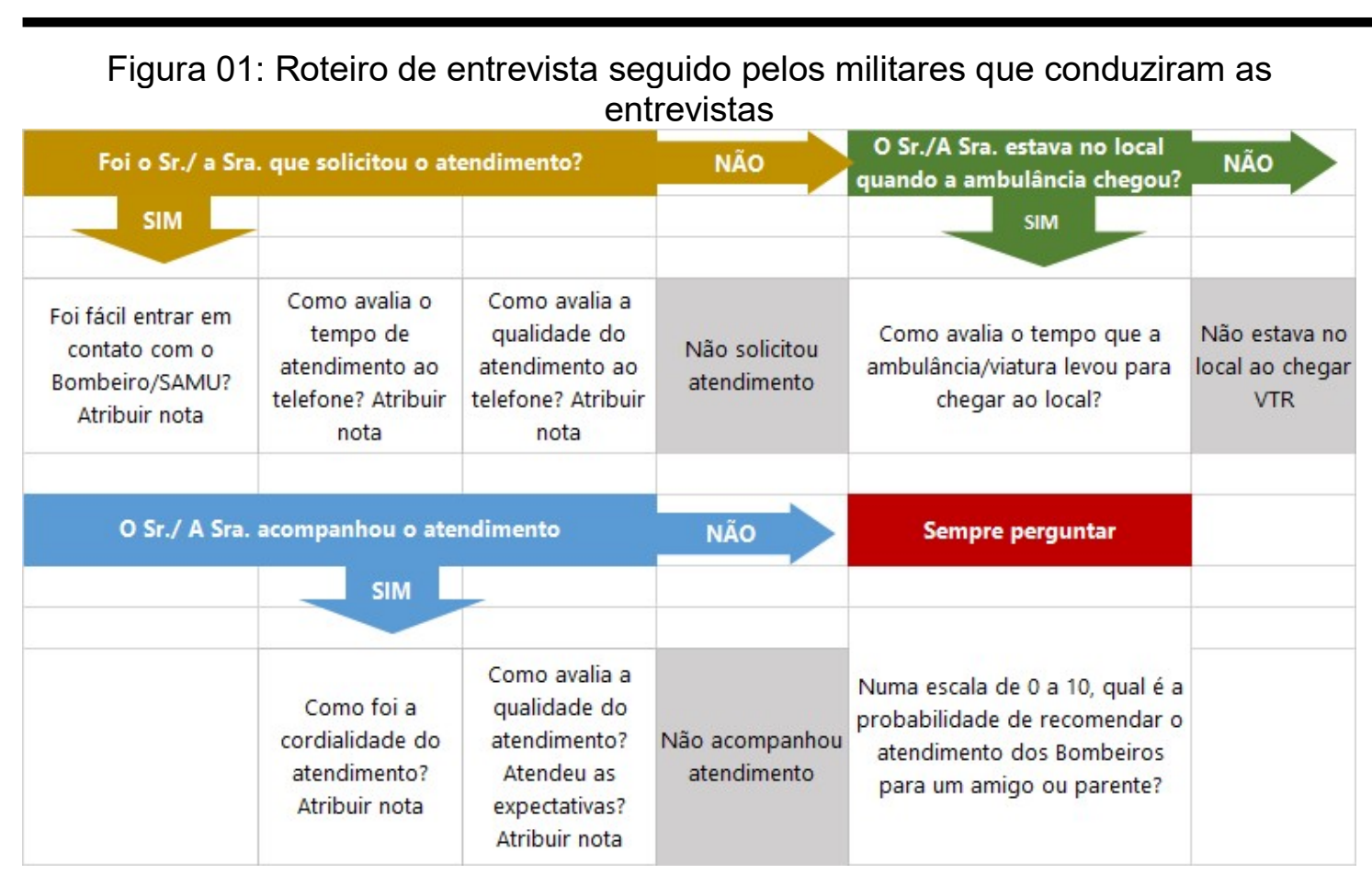

O formulário de coleta de dados foi estruturado em planilha Excel com a sequência de perguntas a ser realizadas em fluxo pelos militares pesquisadores. Os dados obtidos foram lançados sequencialmente na linha com as informações do solicitante e do evento.Visando prevenir desvios dos resultados gerados pela atuação dos pesquisadores, todos os militares que realizaram as ligações foram treinados a partir de roteiro para padronização da entrevista, que compreendeu a apresentação, a realização das perguntas e a interpretação das respostas para lançamento na planilha.

O primeiro bloco de questões buscou avaliar o atendimento telefônico no momento da solicitação do socorro (acesso, duração da ligação e qualidade). 0 segundo bloco tratou da percepção do tempo-resposta e o terceiro da cordialidade e eficiência das guarnições. $O$ quarto bloco composto pela pergunta final foi incluido para aplicação da metodologia do Net Promoter Score (NPS). 
Revista Científica do Corpo de Bombeiros Militar de Pernambuco

Seção 1 - Artigos Técnico Científicos

Artigo publicado no Vol.04 №09 - Edição de JAN a JUN 2018 - ISSN 2359-4837(online)

Versão on-line disponível em: $\underline{\text { http://www.revistaflammae.com. }}$

O NPS é uma ferramenta simples para medir a satisfação do cliente por meio da pergunta "Qual a probabilidade de você recomendar nossa empresa/marca/produto/serviço para um amigo/parente?" com escala de avaliação de 0 (extremamente baixa) a 10 (extremamente alta). 0 objetivo do NPS é determinar um índice de satisfação facilmente interpretável e que pode ser comparado ao longo do tempo ou entre diferentes empresas/instiutições (REICHHELD, 2003). Dependendo da pontuação que é dada à questão, os respondentes são classificados em três categorias, conforme descrito e ilustrado na figura 02 :

Figura 02: Classificação dos usuários pelo Net Promoter Score (NPS): detratores, passivos e promotores

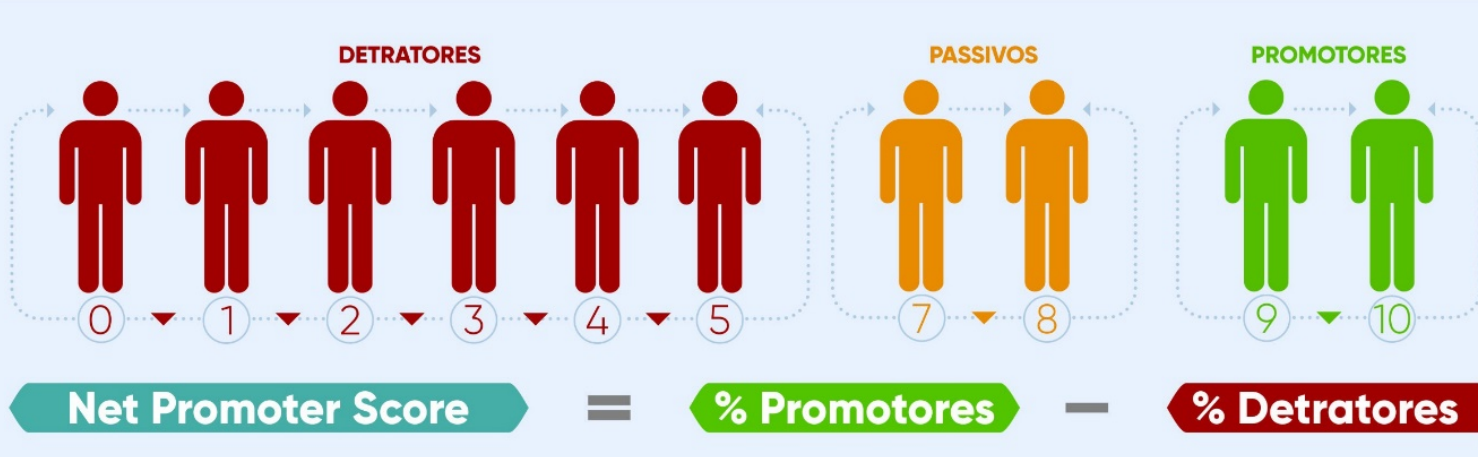

De acordo com o NPS, os usuários detratores são respondentes que atribuíram notas de 0 a 6 (Por estarem insatisfeitos podem "falar mal" da corporação). Os usuários passivos são aqueles indivíduos que destinaramnotas 7 ou 8 ao atendimento (Estão satisfeitos, mas não foram "surpreendidos" ou "encantados" pelo serviço). Já os usuário promotores contemplam os entrevistados que atribuíram notas 9 ou 10 (Esses realmente ficaram satisfeitos com o serviço e passam a fazer "propaganda gratuita", recomendando e até se orgulhando do serviço). 
Revista Científica do Corpo de Bombeiros Militar de Pernambuco

Seção 1 - Artigos Técnico Científicos

Artigo publicado no Vol.04 №09 - Edição de JAN a JUN 2018 - ISSN 2359-4837(online)

Versão on-line disponível em: http://www.revistaflammae.com.

O NPS é calculado como a diferença entre a porcentagem de promotores e detratores. Não é expresso como uma porcentagem, mas como um número absoluto situado entre -100 e +100 .

Os tipos de eventos analisados noProjeto AVALIE compreenderam: (1) os atendimento pré-hospitalares (APH), (2) os acidentes de transporte terrestre (ATT), (3) os incêndios, (4) os atendimentos aos portadores de transtorno mental (PTM) e (5) os salvamentos.

Os dados quantitativos foram consolidados por meio de médias aritméticas e frequências simples. A análise dos achados a partir da aplicação do Net Promoter Score contém, além do índice obtido, uma discussão sobre os fatores com maior indução de geração de usuários detratores, assim como uma comparação dos resultados do CBMERJ com empresas que utilizaram o NPS para avaliação de satisfação dos seus clientes nos últimos anos.

Cabe ressaltar que, para fins do presente artigo, serão apresentados as médias, frequências e índices globais obtidos pelo CBMERJ. O Projeto AVALIE detalhou esses resultados pelos diferentes quartéis da Corporação, de forma a permitir uma análise focada por Organização de Bombeiro Militar (OBM). Esse detalhamento, cuja extensão extrapola o escopo desta publicação, pode ser encontrado no relatório final do referido Projeto (CBMERJ, 2017a).

\section{RESULTADOS}

Dos 3.883 solicitantes entrevistados, $96,4 \%$ verbalizaram aprovação ao trabalho do Corpo de Bombeiros, com notas atribuídas acima de sete, numa escala de zero a dez, sendo que $88,9 \%$ recomendariam o atendimento do CBMERJ com notas nove ou dez, sendo classificados como usuários promotores, segundo a metodologia utilizada no Net Promoter Score.

Tal percentual de aprovação é similar ao Índice de Confiança Social (ICS) do IBOPE, cuja última edição publicada, referente ao ano de 2015, trouxe 
Revista Científica do Corpo de Bombeiros Militar de Pernambuco Seção 1 - Artigos Técnico Científicos Artigo publicado no Vol.04 NN09 - Edição de JAN a JUN 2018 - ISSN 2359-4837(online)

Versão on-line disponível em: http://www.revistaflammae.com.

- Corpo de Bombeiros com índice de aprovação de 81 pontos numa escala de zero a 100, constituindo-se no líder do ranking composto por 18 instituições, que incluíram igrejas, Forças Armadas, meio de comunicação, escolas, empresas, Polícia, Poder Judiciário, entre outras (IBOPE, 2016).

Embora o ICS/IBOPE entreviste a população em geral em âmbito nacional, o percentual de aprovação encontrado no Projeto AVALIE nos deixa o indicativo que essa confiança global na instituição Corpo de Bombeiros não é frustada quando o cidadão fluminense se torna usuário dos serviço do CBMERJ. Ao contrário, seu percentual de aprovação permanece elevado.

O Projeto AVALIE pesquisou aspectos referentes ao atendimento telefônico e ao desempenho das guarnições do CBMERJ. O resultado obtido, por meio de médias aritméticas das notas atribuídas pelos solicitantes ouvidos, evidenciou uma percepção de excelência em ambos os aspectos, como está apresentado nos quadros $01 \mathrm{e} 02$.

Quadro 01: Médias atribuídas ao atendimento telefônico do CBMERJ

\section{ATENDIMENTO TELEFÔNICO}

Facilidade de contato com o CBMERJ

Tempo de atendimento ao telefone

Qualidade de atendimento ao telefone

\section{MÉDIA CBMERJ}

9,20

Quadro 02: Médias atribuídas ao desempenho das guarnições do CBMERJ

\section{ATENDIMENTO DAS GUARNIÇõES MÉDIA CBMERJ}

Cordialidade durante $\mathrm{O}$ atendimento

9,52

Eficiência no atendimento

9,52

Outra questão abordada pela pesquisa foi o tempo-resposta percebido, ou seja, o sentimento do solicitante em relação ao tempo despendido até a chegada da viatura no local do evento. Nesse aspecto, $79,2 \%$ dos participantes classificaram o tempo como satisfatório (dentro do esperado ou mais rápido 


\section{Revista FLAMMAE}

Revista Científica do Corpo de Bombeiros Militar de Pernambuco

Seção 1 - Artigos Técnico Científicos

Artigo publicado no Vol.04 №09 - Edição de JAN a JUN 2018 - ISSN 2359-4837(online)

Versão on-line disponível em: http://www.revistaflammae.com.

que o esperado). $\mathrm{O}$ detalhamento do tempo-resposta percebido está apresentado na figura 3

Figura 3: Gráfico de Tempo-reposta percebido pelos solicitantes entrevistados TEMPO-RESPOSTA PERCEBIDO

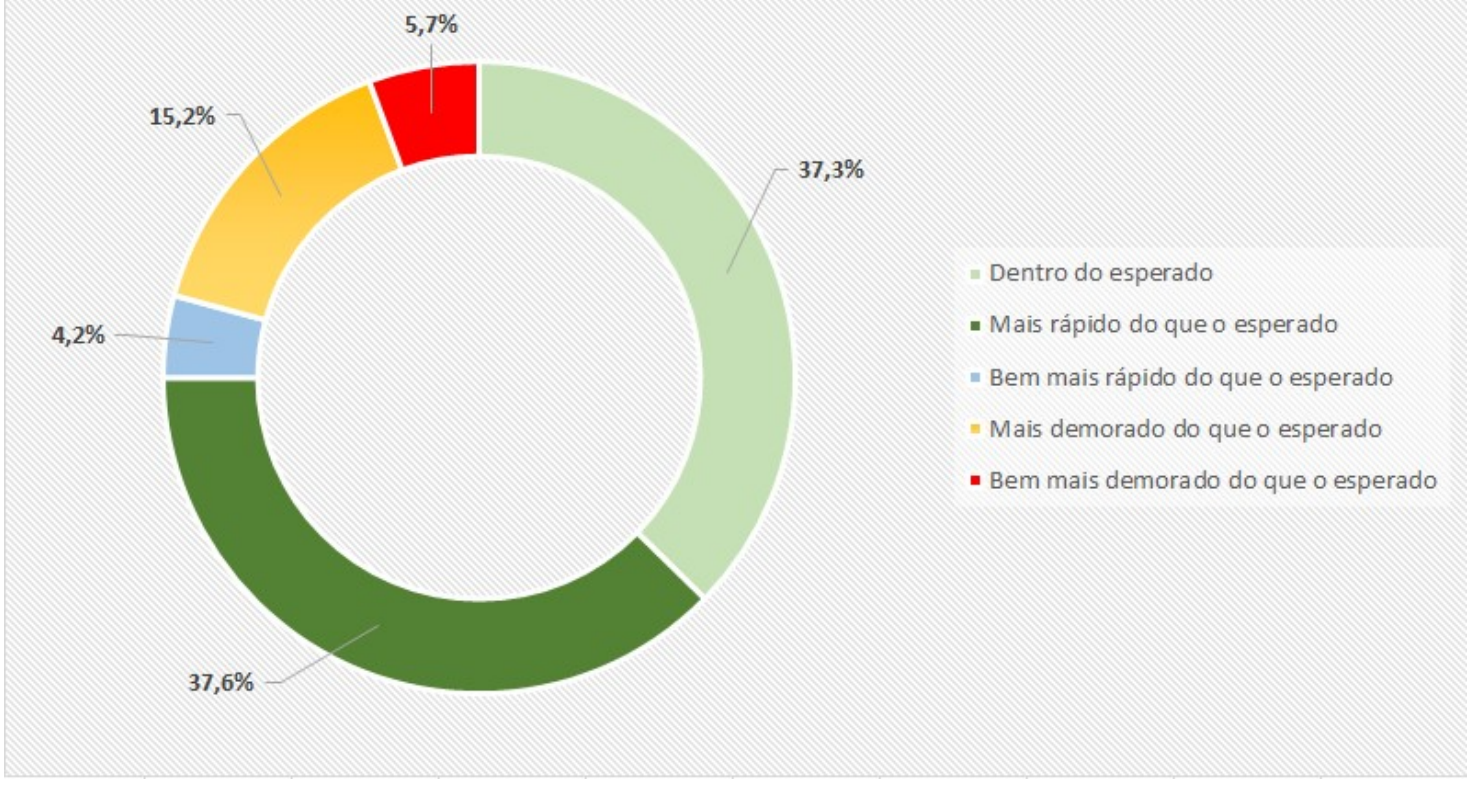

Dentre os 3.883 solicitantes encontrados e ouvidos pela pesquisa 1.001 acionaram o socorro para eventos de incêndio e afins, 952 para salvamentos, 917 para acidentes de transporte terrestre, 670 para atendimento pré-hospitalar e 343 para atendimento ao portador de transtorno mental (PTM).

Cabe esclarecer que embora o APH responda por $55,8 \%$ dos socorros realizados pela corporação (CBMERJ, 2017b), dificuldades de relacionar os eventos com os quartéis na base utilizada para pesquisa limitaram o número de solicitantes encontrados. Com relação ao atendimento ao PTM, sua representatividade menor já era esperada, posto que este tipo de socorro tem maior expressão apenas na capital do Rio de Janeiro.

O desempenho das guarnições por tipo de evento, mensurado em média aritmética das notas atribuídas pelos entrevistados, variou de 9,34 a 9,68, conforme apresentado no quadro 03 


\section{Revista FLAMMAE}

Revista Científica do Corpo de Bombeiros Militar de Pernambuco Seção 1 - Artigos Técnico Científicos

Artigo publicado no Vol.04 No09 - Edição de JAN a JUN 2018 - ISSN 2359-4837(online)

Versão on-line disponível em: http://www.revistaflammae.com.

Quadro 03: Médias atribuídas ao desempenho das guarnições do CBMERJ por tipo de evento

\section{TIPO DE EVENTO}

MÉDIA CBMERJ

\begin{tabular}{|l|l|}
\hline Acidente de Transporte Terrestre - ATT & $\mathbf{9 , 6 8}$ \\
\hline Salvamento & $\mathbf{9 , 5 4}$ \\
\hline Incêndio & $\mathbf{9 , 4 7}$ \\
\hline Atendimento Pré-Hospitalar - APH & $\mathbf{9 , 4 5}$ \\
\hline Atendimento ao Portador de Transtorno Mental - PTM & $\mathbf{9 , 3 4}$ \\
\hline
\end{tabular}

Os quadros que se seguem apresentam o desempenho das guarnições pelos principais tipos/subtipos de atendimento pré-hospitalar, incêndio e salvamento.

Quadro 04: Médias atribuídas ao desempenho das guarnições do CBMERJ por tipo de APH

\section{TIPOS DE ATENDIMENTO PRÉ-HOSPITALAR (APH)}

MÉDIA CBMERJ

1. Atendimento ao trauma

9,63

2. Atendimento clínico

9,39

3. Atendimento obstétrico

9,00

Quadro 05: Médias atribuídas ao desempenho das guarnições do CBMERJ por tipo e subtipo de incêndio

TIPOS E SUBTIPOS DE INCÊNDIO E AFINS

MÉDIA CBMERJ

\begin{tabular}{|l|l|}
\hline 1. Fogo em edificação & $\mathbf{9 , 6 2}$ \\
\hline 2. Fogo em veículo & $\mathbf{9 , 5 6}$ \\
\hline 3. Escapamento de gás & $\mathbf{9 , 5 5}$ \\
\hline 4. Fogo em vegetação & $\mathbf{9 , 3 4}$ \\
\hline 4.1. em Área de Proteção Ambiental & $\mathbf{9 , 6 0}$ \\
\hline 4.2. em morro & $\mathbf{9 , 4 9}$ \\
\hline 4.3. em terreno com edificação & $\mathbf{9 , 2 6}$ \\
\hline 4.4. em terreno baldio & $\mathbf{9 , 1 0}$ \\
\hline 5. Fogo em via pública & $\mathbf{9 , 3 2}$ \\
\hline 5.1. em amontoado de lixo & $\mathbf{9 , 5 8}$ \\
\hline 5.2. em poste & $\mathbf{9 , 1 2}$ \\
\hline 5.3. em transformador & $\mathbf{8 , 0 0}$ \\
\hline
\end{tabular}


Revista Científica do Corpo de Bombeiros Militar de Pernambuco Seção 1 - Artigos Técnico Científicos

Artigo publicado no Vol.04 №09 - Edição de JAN a JUN 2018 - ISSN 2359-4837(online)

Versão on-line disponível em: http://www.revistaflammae.com.

Quadro 06: Médias atribuídas ao desempenho das guarnições do CBMERJ por tipo e subtipo de salvamento

\section{TIPOS E SUBTIPOS DE SALVAMENTOS}

\section{MÉDIA CBMERJ}

1. Busca de pessoas

9,82

2. Arrombamento

9,76

3. Salvamento de pessoa

9,67

3.1. em tentativa de suicídio

9,78

3.2. em elevador

9,75

3.3. em edificação

9,70

3.4. em outros locais*

9,35

3.5. em mata

9,00

4. Captura/retirada de animal

9,45

4.1. de aves em geral

9,92

4.2. de gambá

9,76

4.3. de cobra

9,75

4.4. de jacaré

9,62

4.5. de cachorro

9,25

4.6. de cavalo

9,13

4.7. de gato

9,06

4.8. de boi/vaca

8,00

5. Desabamento

9,20

6. Delizamento

9,00

* em outros locais compreende o salvamento de pessoas em encostas, escadas, lagos, locais confinados, poços, postes, rios e locais não especificados na base de dados utilizadas.

Nesse contexto de análise dos tipos de evento, foi possível observar que o tempo-resposta percebido como satisfatório variou dependendo do grupo de evento, conforme apresentado na figura 04 . Na avaliação dos solicitantes, os acidentes de transporte terrestre e os salvamentos apresentaram um percentual de satisfação com o tempo-resposta superior à média CBMERJ. Já os atendimentos pré-hospitalares, os incêndios e os socorros aos portadores de transtorno mental se localizaram abaixo da média da corporação que, como visto anteriormente, foi de $79,2 \%$. 
Revista Científica do Corpo de Bombeiros Militar de Pernambuco Seção 1 - Artigos Técnico Científicos

Artigo publicado no Vol.04 No09 - Edição de JAN a JUN 2018 - ISSN 2359-4837(online)

Versão on-line disponível em: http://www.revistaflammae.com.

Figura 04: Gráfico Tempo-reposta percebido como satisfatório pelos solicitantes entrevistados estratificado por grupo de evento

TEMPO-RESPOSTA PERCEBIDO COMO SATISFATÓRIO POR GRUPO DE EVENTO

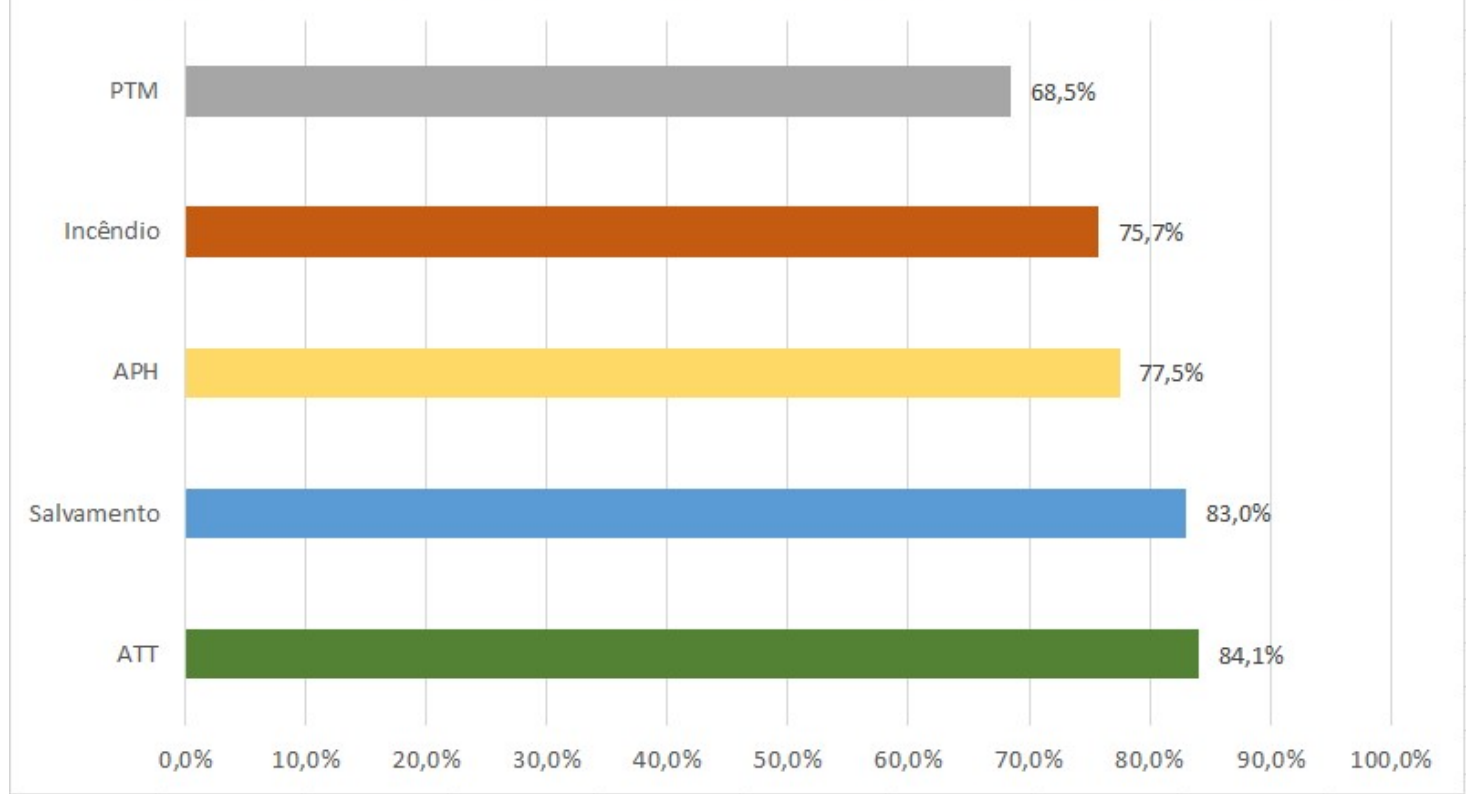

O percentual de usuários promotores, ou seja, de entrevistados que recomendariam o atendimento do CBMERJ com nota 9 ou 10, encontrado na pesquisa foi de $88,9 \%$. Já os usuários detratores, aqueles que atribuíram notas iguais ou menores que 6 quando solicitados a quantificar o grau de recomendação dos serviços do Corpo de Bombeiros,foi de 3,6\%.

Como apresentado na Metodologia, o NPS mede a satisfação geral e lealdade do cliente/usuário em relação à empresa/instituição. O score é calculado subtraindo a porcentagem de detratores do percentual de promotores, o que gera um valor entre -100 e 100. Assim sendo, o NPS do CBMERJ foi 85,5. Trata-se de resultado que denota elevadíssimo índice de satisfação.

Para auxiliar na compreensão do significado desse valor, plotamos o score do CBMERJ na figura 05 ao lado de algumas marcas internacionalmente conhecidas, que utilizaram o NPS e divulgaram seus resultados. 
Revista Científica do Corpo de Bombeiros Militar de Pernambuco

Seção 1 - Artigos Técnico Científicos

Artigo publicado no Vol.04 No09 - Edição de JAN a JUN 2018 - ISSN 2359-4837(online)

Versão on-line disponível em: http://www.revistaflammae.com.

Figura 05: Gráfico Benchmark entre NPS do CBMERJ e empresas internacionalmente conhecidas

NET PROMOTER SCORE (NPS): CBMERJ E OUTRAS EMPRESAS/MARCAS

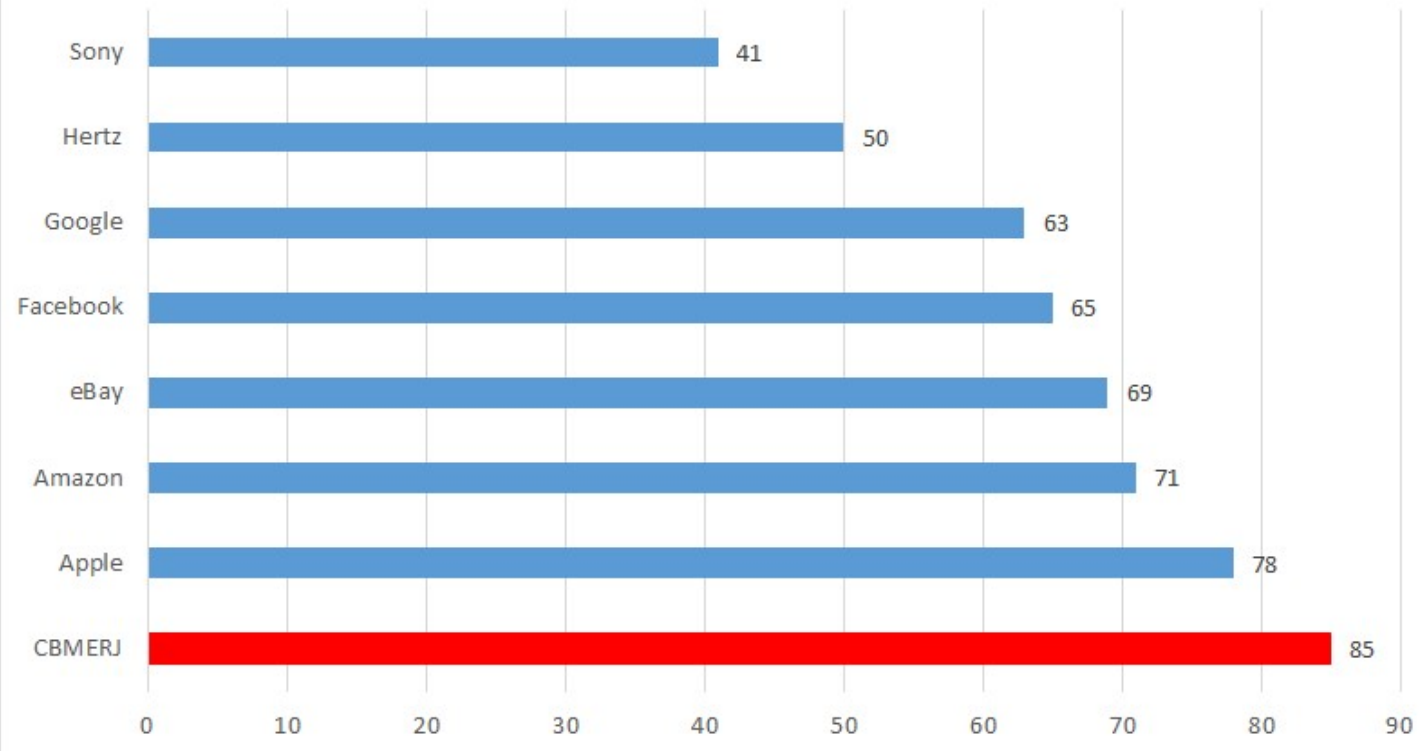

De acordo com Almeida (2014), não basta se conhecer e aplicar o NPS. As empresas e instituições precisam trabalhar com essa ferramenta avaliativa no seu cotidiano, gerando melhorias operacionais. O autor afirma que "é importante saber como se beneficiar dos resultados obtidos com o NPS, utilizando-os de forma contínua, conseguindo entender os porquês de cada usuário, alcançando assim um número maior de promotores" (ALMEIDA, 2014, p. 17). É exatamente o que o CBMERJ vem realizando a partir da instauração do Projeto AVALIE. Os resultados do NPS por quartel vêm sendo analisados de forma quanti-qualitativa e servindo de ponto de partida para ampliação do número de promotores e redução de detratores por meio do Plano de Metas institucional, coordenado pelo Estado-Maior Geral.

Além do trabalho de análise individualizada por quartel, julgou-se interessante proceder uma análise relacional dos usuários detratores com o tipo de evento e grau de satisfação nas diferentes etapas do atendimento, 
Revista Científica do Corpo de Bombeiros Militar de Pernambuco

Seção 1 - Artigos Técnico Científicos

Artigo publicado no Vol.04 №09 - Edição de JAN a JUN 2018 - ISSN 2359-4837(online)

Versão on-line disponível em: http://www.revistaflammae.com.

buscando estabelecer algumas relações que poderão ser monitoradas com vistas à melhoria da qualidade do atendimento e da satisfação da população.

Foram encontrados 138 usuários detratores na amostra de 3.883 participantes. Em termos absolutos, os incêndios e afins foram o grupo de eventos com o maior número de detratores. No entanto, considerando que dentre os solicitantes que participaram da pesquisa o total de eventos por categoria guardou diferenças expressivas (1001 incêndios, 952 salvamentos, 917 acidentes de transporte terrestre, 670 atendimentos pré-hospitalares e 343 atendimentos a portadores de transtorno mental), uma análise proporcional se fez necessária, a qual revelou que o atendimento ao portador de transtorno mental foi o evento que teve o maior percentual relativo de detratores por categoria de evento, como está apresentado na figura 06.

Figura 06: Gráfico Percentual relativo de usuários detratores (NPS) por categoria de eventos

\section{PERCENTUAL RELATIVO DE DETRATORES POR CATEGORIA DE EVENTO}

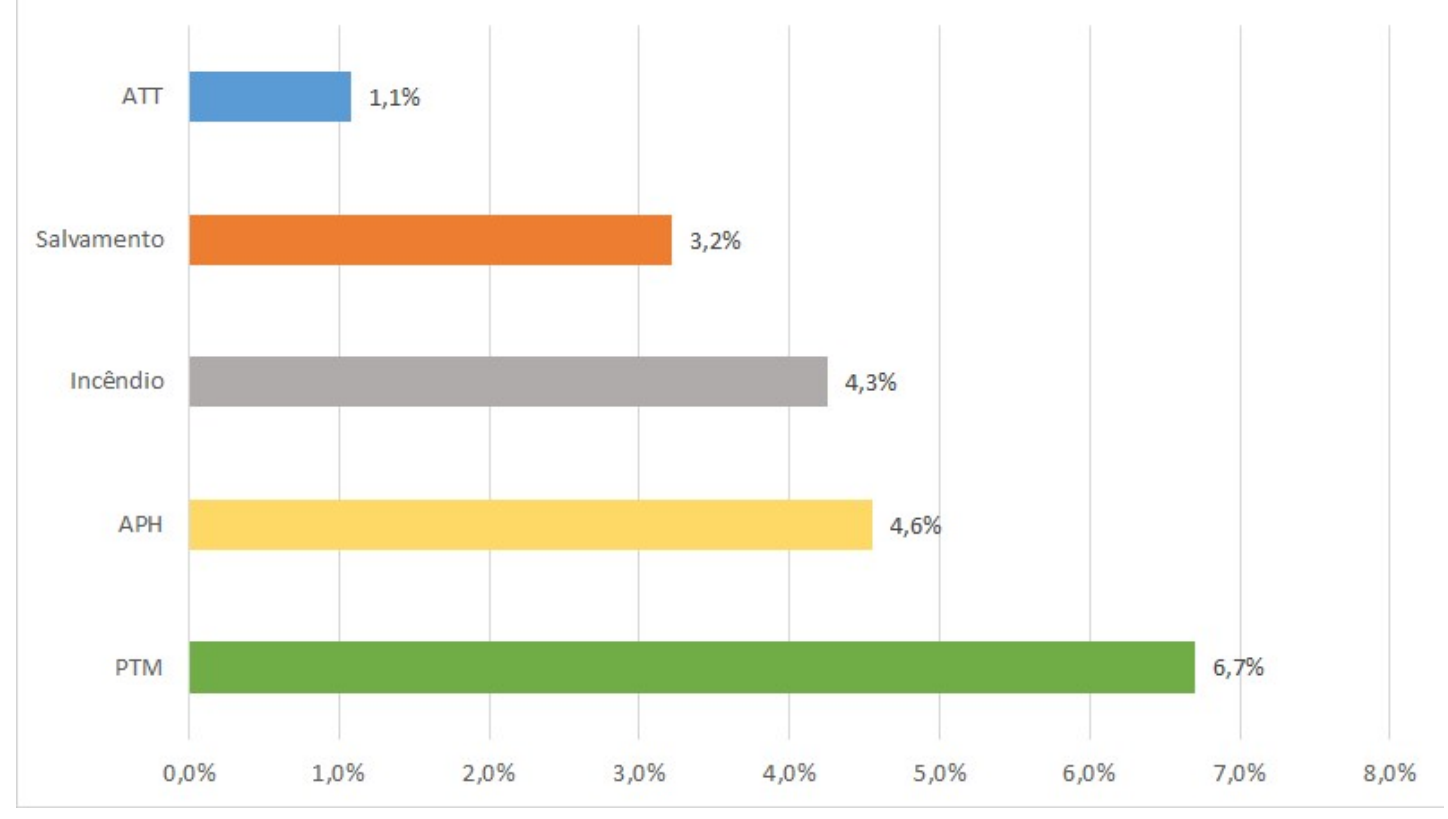

Uma análise da distribuição dos detratores por grupo de eventos, sem a anterior ressalva da proporcionalidade do número de eventos avaliados, mostra 


\section{Revista FLAMMAE}

Revista Científica do Corpo de Bombeiros Militar de Pernambuco Seção 1 - Artigos Técnico Científicos

Artigo publicado no Vol.04 No09 - Edição de JAN a JUN 2018 - ISSN 2359-4837(online)

Versão on-line disponível em: http://www.revistaflammae.com.

os incêndios como os eventos com o maior número absoluto de detratores (43/138), seguidos do atendimento pré-hospitalares (31/138) e salvamentos (31/138). Por fim, estão os atendimentos aos portadores de transtorno mental (23/138) e os acidentes de transporte terrestre (10/138). Tal distribuição está apresentada na figura 07.

Figura 7: Gráfico Percentual absoluto de usuários detratores (NPS) por categoria de eventos

PERCENTUAL ABSOLUTO DE DETRATORES POR CATEGORIA DE EVENTO

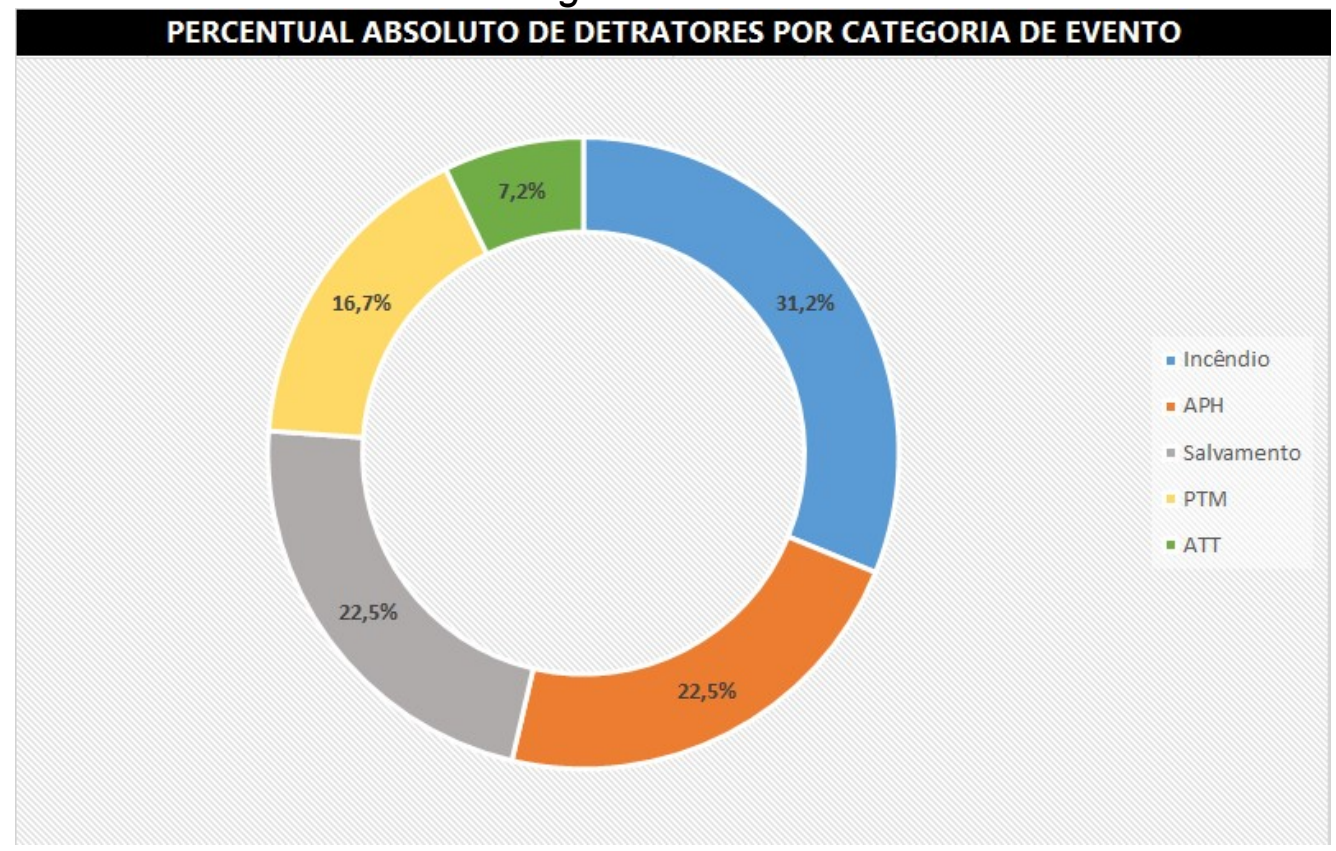

Um olhar mais detalhado por tipos de eventos revela alguns aspectos interessantes: dentre os atendimentos pré-hospitalares, a maior concentração de detratores ocorreu nos socorros clínicos. Já entre os incêndios os detratores se localizaram predominantemente nas solicitações de fogo em vegetação. O mesmo ocorreu para captura/retirada de animal dentre os salvamentos. As figuras 08,09 e 10 ilustram esta análise.

Figura 8: Gráfico de Distribuição percentual de usuários detratores (NPS) por tipo de $A P H$ 


\section{Revista FLAMMAE}

Revista Científica do Corpo de Bombeiros Militar de Pernambuco

Seção 1 - Artigos Técnico Científicos

Artigo publicado no Vol.04 Nº9 - Edição de JAN a JUN 2018 - ISSN 2359-4837(online)

Versão on-line disponível em: http://www.revistaflammae.com.

\section{DISTRIBUIÇÃO DOS DETRATORES POR TIPO DE APH}

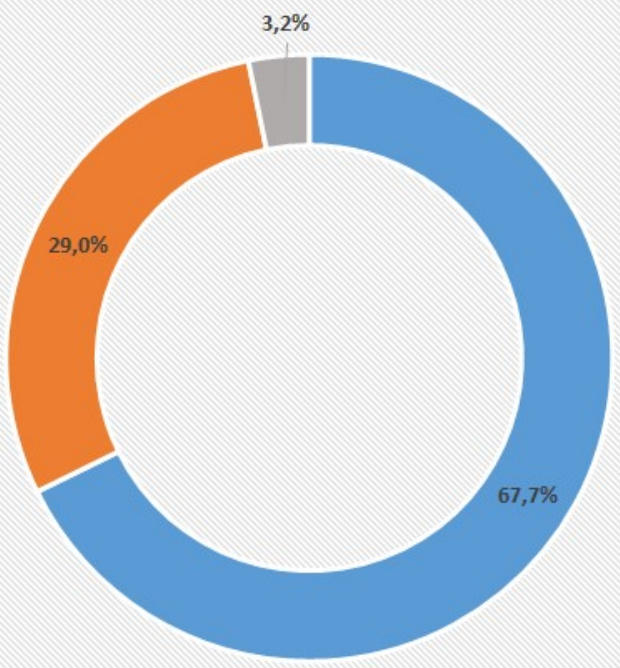

- Clinico

- Trauma

- Obstétrico

Figura 09: Gráfico de Distribuição percentual de usuários detratores (NPS) por tipo de incêndio

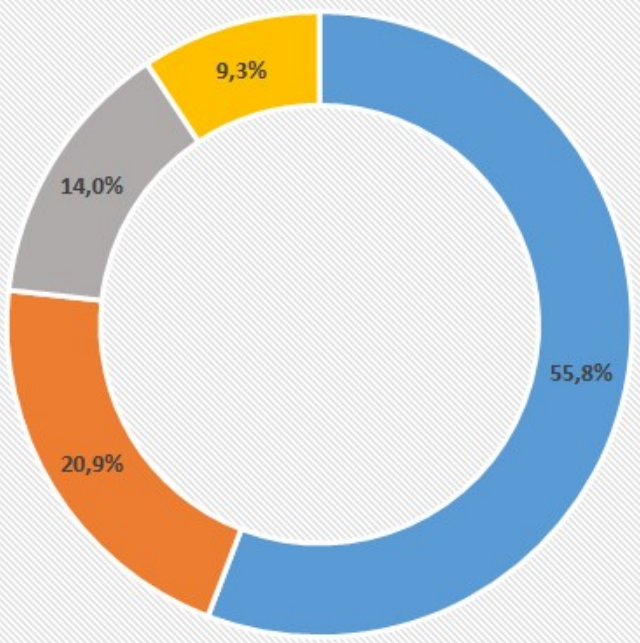

- Fogo em vegetação

- Fogo em via pública

- Fogo em edificação

- Escapamento de gás 


\section{Revista FLAMMAE}

Revista Científica do Corpo de Bombeiros Militar de Pernambuco

Seção 1 - Artigos Técnico Científicos

Artigo publicado no Vol.04 №09 - Edição de JAN a JUN 2018 - ISSN 2359-4837(online)

Versão on-line disponível em: http://www.revistaflammae.com.

Figura 10: Gráfico da Distribuição percentual de usuários detratores (NPS) por tipo de salvamento

\section{DISTRIBUIÇÃO DOS DETRATORES POR TIPO DE SALVAMENTO}

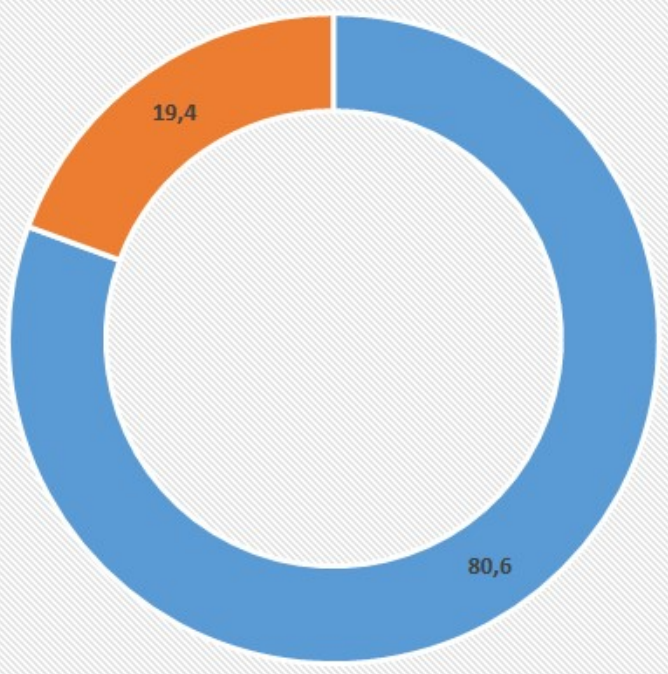

- Captura/retirada de animal

- Salvamento de pessoa

Além da análise relacional dos detratores e os tipos de eventos, buscouse estabelecer correlação entre tais usuários e a qualidade do atendimento telefônico e da guarnição. Para tal levantou-se, dentre os detratores, o percentual de avaliações abaixo de 6 para as duas etapas de atendimento (telefone e guarnição). Dos 138 usuários detratores, 74 atribuíram notas inferiores a 6 para o atendimento telefônico, enquanto 45 o fizeram para a avaliação da qualidade da assistência da guarnição, o que revela o significativo potencial ofensor da experiência de solicitação de socorro ao telefone para a imagem da corporação. Este comparativo percentual está apresentado na figura 11. 


\section{Revista FLAMMAE}

Revista Científica do Corpo de Bombeiros Militar de Pernambuco Seção 1 - Artigos Técnico Científicos

Artigo publicado no Vol.04 No09 - Edição de JAN a JUN 2018 - ISSN 2359-4837(online)

Versão on-line disponível em: http://www.revistaflammae.com.

Figura 11: Gráfico da Relação entre usuários detratores (NPS) e qualidade do atendimento telefônico e das guarnições

RELAÇÃO ENTRE DETRATORES E QUALIDADE DO ATENDIMENTO TELEFÔNICO E DA GUARNIÇÃO

Detratores que atribuiram notas $\leq 6$ para o atendimento

da guarnição

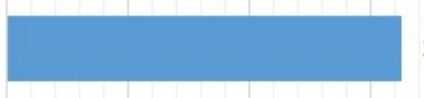

$32,60 \%$

Detratores que atribuiram notas $\leq 6$ para o atendimento telefônico

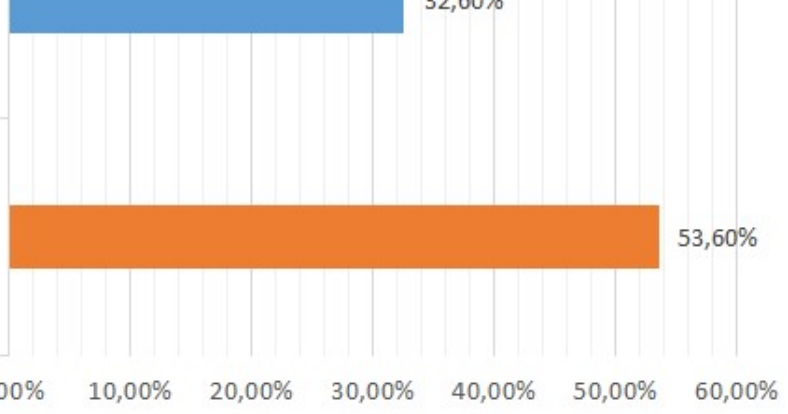

Por fim, averiguou-se a relação entre usuários detratores e o tempo-reposta percebido, o que segue apresentado na figura 12.

Figura 12: Gráfico da Relação entre usuários detratores (NPS) e temporesposta percebido

\section{RELAÇÃO ENTRE DETRATORES E TEMPO-RESPOSTA PERCEBIDO}

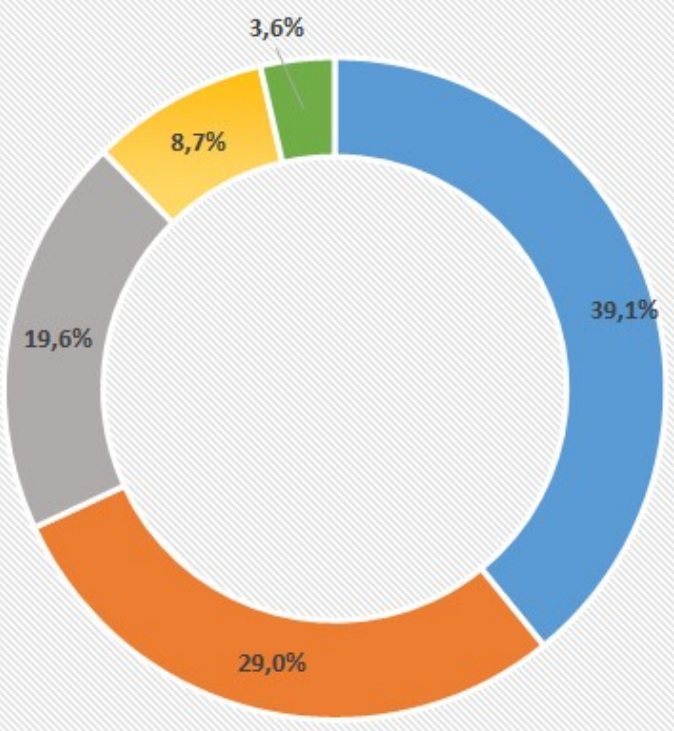

- Não soube avaliar

- Bem mais demorado que o esperado

- Mais demorado que o esperado

- Dentro do esperado

- Mais rápido do que o esperado 
Revista Científica do Corpo de Bombeiros Militar de Pernambuco

Seção 1 - Artigos Técnico Científicos

Artigo publicado no Vol.04 N09 - Edição de JAN a JUN 2018 - ISSN 2359-4837(online)

Versão on-line disponível em: http://www.revistaflammae.com.

O gráfico anterior demonstra uma relação importante entre demora percebida na chegada do socorro e usuários detratores. Apenas 12,3\% deles estavam satisfeitos com o tempo resposta. Outro aspecto importante a ser ressaltado é a grande quantidade de usuários detratores que não souberam avaliar o tempo de chegada das viaturas. A experiência dos militares pesquisadores durante o período das ligações, revelou relatos importantes de insatisfação em solicitações para as quais não foram enviadas viaturas. Parte dos detratores incluídos na categoria "não soube avaliar" reflete essa realidade.

Além dos índices apresentados, algumas impressões captadas pelos pesquisadores a partir de relatos repetidos dos solicitantes forma registradas e seguem sintetizadas de forma a complementar os dados quantitativos.

Dentre os solicitantes localizados pela equipe de pesquisa, a receptividade foi muito boa. Em geral, as pessoas responderam às questões com cordialidade e não raro discorreram sobre a vivência do socorro relatando grande sentimento de gratidão e respeito ao CBMERJ. Um aspecto muito interessante percebido pelos militares da equipe técnica do projeto foi o fato de que entrar em contato com as pessoas para que elas avaliassem 0 atendimento recebido pelo CBMERJ gerou um sentimento nos solicitantes de zelo por parte da corporação. De forma recorrente, houve menção de aprovação à iniciativa das ligações por meio de relatos de satisfação diante da preocupação do CBMERJ em saber como tinham sido atendidos os usuários dos seus serviços.

Um relato enfático repetido por muitos participantes da pesquisa foi a percepção do Corpo de Bombeiros como um serviço público eficiente e de qualidade. Com frequência as pessoas tratavam o tema como algo admirável contextualizando as falas a partir de concepções de um cenário conjuntural de descrença nas instituições governamentais. Solicitados a atribuir notas numa escala de 0 a 10 para o CBMERJ, muitos solicitantes respondiam efusivamente com 100 ou 1000, numa demonstração de grande apreço ao trabalho desenvolvido pelo Corpo de Bombeiros. 
Revista Científica do Corpo de Bombeiros Militar de Pernambuco

Seção 1 - Artigos Técnico Científicos

Artigo publicado no Vol.04 N09 - Edição de JAN a JUN 2018 - ISSN 2359-4837(online)

Versão on-line disponível em: http://www.revistaflammae.com.

Um fenômeno relativamente recorrente surpreendeu a equipe de militares do projeto. Se percebeu que em muitos casos, o solicitante reclamava de algum aspecto do atendimento e atribuía notas baixas baseado na experiência de socorro vivenciada no ano de 2016. No entanto, ao final, quando perguntado com que nota recomendaria o atendimento do Corpo de Bombeiros de uma maneira geral para um parente ou amigo, as notas eram 9 ou 10. Ou seja, mesmo diante de determinadas experiências negativas no atendimento foco da avaliação, os solicitantes se mantiveram como usuários promotores no NPS. Essa observação foi surpreendente pois se repetiu inúmeras vezes e despertou uma reflexão sobre a fortaleza da imagem institucional do CBMERJ.

Durante as avaliações dos solicitantes, o atendimento telefônico do CBMERJ recebeu elogios e críticas. Dentre a fortaleza mencionada por vários solicitantes esteve a qualidade das orientações e apoio da figura do comunicante/atendente durante o deslocamento das viaturas. Os participantes relataram como foram devidamente acalmados e receberam instruções importantes no momento da urgência. Por outro lado, com certa recorrência, críticas foram feitas à quantidade de perguntas feitas para confirmação de um socorro, muitas das quais na avaliação dos solicitantes poderiam ser suprimidas. O que se pode extrair da conversa com as pessoas é que diante de uma emergência, as pessoas desejam um atendimento objetivo e chegam a se desesperar diante de muitas perguntas.

O projeto AVALIE analisou o tempo-resposta percebido não pretendendo realizar inferências técnicas sobre o período ideal para o socorro nas diferentes situações de urgência. O objetivo foi analisar como os usuários percebiam o tempo que o socorro demorou a chegar, se estava dentro, abaixo ou acima do esperado. O que se notou numa análise qualitativa dos diálogos como os participantes foi a relativização do tempo resposta. Algumas pessoas diziam que o socorro havia chegado em 20 minutos e classificavam como uma resposta mais demorada do que o esperado. Por outro lado, houve quem 
Revista Científica do Corpo de Bombeiros Militar de Pernambuco

Seção 1 - Artigos Técnico Científicos

Artigo publicado no Vol.04 NN09 - Edição de JAN a JUN 2018 - ISSN 2359-4837(online)

Versão on-line disponível em: http://www.revistaflammae.com.

dissesse que o socorro chegou em 40 minutos e que foi muito rápido. Das conversas com os solicitantes, a equipe de militares que efetuou as ligações extraiu duas impressões dessa subjetividade na classificação do temporesposta como satisfatório ou não. A primeira trata da localidade: moradores de grandes centros urbanos pareceram mais tolerantes com o tempo de chegada das viaturas. Muitos deles inclusive faziam ponderações sobre o trânsito no momento de responder à pergunta sobre o tempo que o socorro levou para chegar. Outra variável percebida foi a gravidade do evento que gerou a solicitação. Ocorrências de baixa complexidade e risco geraram maior complacência com relação ao tempo de chegada das viaturas.

Ainda com relação ao tempo-resposta, muito solicitantes que classificaram a chegada do socorro como mais rápida do que o esperado, mencionaram o atendimento pelas motocicletas do CBMERJ.

A percepção de qualidade do atendimento do CBMERJ ficou clara por meio da análise quantitativa já apresentada, em especial pelo NPS, o qual indicou a dimensão da solidez e fortaleza da imagem do CBMERJ. Cabe-nos complementar que dois aspectos relevantes foram repetidamente narrados pelos solicitantes durante as ligações como fatos geradores de grande respeito e admiração pela corporação e seus militares. O primeiro deles está no campo da humanização do socorro: a cordialidade, a atenção e o apoio das guarnições em diversas situações de socorro foi destacada por muitos participantes. E o outro aspecto exposto inúmeras vezes pelos participantes foi a resolubilidade do atendimento. A descrição da eficiência em diversas situações de emergência foi enaltecida por muitos solicitantes com narrativas emocionadas e entusiasmadas. Sendo assim, extrai-se da experiência de falar com 3.883 usuários dos serviços do CBMERJ que o pronto atendimento eficaz e humanizado é a garantia da manutenção da imagem de qualidade do nosso Corpo de Bombeiros. 
Revista Científica do Corpo de Bombeiros Militar de Pernambuco

Seção 1 - Artigos Técnico Científicos

Artigo publicado no Vol.04 NN09 - Edição de JAN a JUN 2018 - ISSN 2359-4837(online)

Versão on-line disponível em: http://www.revistaflammae.com.

\section{CONCLUSÃO}

Os objetivos inicialmente propostos foram alcançados. Por meio do Projeto Avalie, é possível afirmar, com base numa análise sistematizada e atual, que o Corpo de Bombeiros Militar do Estado do Rio de Janeiro tem excelente aprovação dentre os usuários de seus serviços.

Diante da predominância absoluta de médias superiores a 9 nos aspectos avaliados e do reconhecimento do CBMERJ como um serviço público respeitável e eficiente, ficam evidentes a qualidade técnica e o comprometimento da tropa, garantidos pela hierarquia e disciplina, características inerentes da condição militar da corporação.

Atualmente, o Projeto Avalie está ganhando em novo formato processual, cujo foco é sua transformação em instrumento de diagnóstico contínuo e acompanhamento permanente para melhoria da qualidade do atendimento por parte das unidades operacionais do CBMERJ. Além disso, seus resultados serviram de base para construção de metas específicas para os quartéis no ciclo 2017/2018 de planejamento institucional.

\section{REFERÊNCIAS}

ALMEIDA, Jadeilton. Net Promoter Score: ferramenta de apoio às decisões estratégicas de marketing de serviços. Trabalho de Conclusão de Curso Bacharelado em Administração. Universidade Estadual da Paraíba. Campina Grande, 2014.

BORGES JUNIOR, Adilson Adão; FONSECA, Marcelo Jacques. O uso da pesquisa de satisfação do consumidor como instrumento de política pública. RIMAR - Revista Interdisciplinar de Marketing. Maringá, 2002, v. 1, n. 3, p. 38-50.

CORPO DE BOMBEIROS MILITAR DO ESTADO DO RIO DE JANEIRO CBMERJ. ESTADO MAIOR GERAL. Projeto AVALIE: análise de satisfação dos solicitantes de socorro ao CBMERJ em 2016. Rio de Janeiro: EMG/CBMERJ, 2017a. 
Revista Científica do Corpo de Bombeiros Militar de Pernambuco Seção 1 - Artigos Técnico Científicos

Artigo publicado no Vol.04 N009 - Edição de JAN a JUN 2018 - ISSN 2359-4837(online)

Versão on-line disponível em: http://www.revistaflammae.com.

CORPO DE BOMBEIROS MILITAR DO ESTADO DO RIO DE JANEIRO CBMERJ. ESTADO MAIOR GERAL. Anuário do CBMERJ 2016. Rio de Janeiro: EMG/CBMERJ, 2017b.

ESPERIDIÃO, Monique Azevedo; TRAD, Leny Alves Bomfim. Avaliação da satisfação de usuários: considerações teórico-conceituais. Cad. Saúde Pública. Rio de Janeiro, 2006, v. 22, n. 6, p. 1267-1276.

INSTITUTO BRASILEIRO DE OPINIÃO PÚBLICA E ESTATÍSTICA. Índice de Confiança Social 2015. Rio de Janeiro: IBOPE, 2015.

REICHHELD, Fred. A pergunta definitiva 2.0. Rio de Janeiro: Campus, 2011.

REICHHELD, Fred. The one number you need to grow. Cambridge: Harvard Business Review, 2003. 